$d r$ Sonja

Kump

Filozofska

fakulteta $v$

Ljubljani

\section{VLOGA SOCIALNEGA KAPITALA V IZOBRAŽEVANJU ODRASLIH}

$\mathrm{Za}$ andragoško teorijo in prakso je razumevanje konceptualnih okvirov pojma socialnega kapitala aktualno, kajti ta vrsta kapitala ima lahko produktivno vlogo pri spodbujanju in razvoju izobraževanja, prav tako pa ima pomembno vlogo tudi pri pojasnjevanju izobraževalnih dosežkov učenja. Pojem socialnega kapitala lahko zasledimo v mnogih novejših družboslovnih razpravah, posredneje pa tudi $\mathrm{v}$ retoriki politike. Leta 2000 so na primer predsedniki držav EU v Lizboni podpisali Memorandum o vseživljenskem učenju (www.europa.eu.int/ comm/education/life/), v katerem je velik poudarek na socialni povezanosti, uspo-

Je socialni kapital $\checkmark$ lasti skupine ali posameznika? sabljanju ljudi za aktivno sodelovanje na vseh ravneh in socialnem partnerstvu nacionalnih, regionalnih in lokalnih oblasti, strokovnih organizacij $\mathrm{v}$ izobraževanju, organizacij civilne družbe in tudi posameznikov.

Zlasti ekonomisti in sociologi so prepričani, da je socialni kapital enako pomemben kot fizični in človeški kapital, ko pojasnjujejo socialne razlike, razlike $\mathrm{v}$ individualni ter civilni blaginji in predvsem pri razlagah različnih nacionalnih donosov. Čeprav deluje socialni kapital ločeno od ekonomske sfere, pomembno vpliva nanjo. Potenciali socialne- ga kapitala se kažejo na številnih področjih, kot so izobraževanje, gospodarstvo, socialna mobilnost, politika itn. Da je pojem izredno aktualen tudi v Sloveniji, dokazuje razpis Ministrstva za šolstvo, znanost in šport, saj se ena od prioritetnih tem $v$ razpisu za izbiro raziskovalno-razvojnih projektov ciljnega raziskovalnega programa Konkurenčnost Slovenije 2001-2006 (www.mzt.si/mzt/ tenders/crp/2001/razp-crp-konkur-01.html) nanaša na človeške vire in socialno kohezivnost, torej na področje socialnega in človeškega kapitala.

\section{KONCEPTI SOCIALNEGA KAPITALA}

$\mathrm{V}$ literaturi zasledimo dve prevladujoči interpretaciji socialnega kapitala. Normativno funkcionalistična različica (Coleman, Putnam, Fukuyama in Etzioni) razume socialni kapital kot norme in odnose, ki povezujejo skupnosti z reciprociteto, zaupanjem in vpeljevanjem sankcij za odklone od naštetega. Poudarja pomen zaloge človeških odnosov kot osnove za generiranje človeškega ter fizičnega kapitala in koristi, ki jih ima od socialnega kapitala širša skupnost. Socialni kapital je torej v lasti socialne skupine, in ne posameznikov. Horizontalne mreže med enakimi imajo prednost pred vertikalnimi mrežami, ki temeljijo na avtoritarnih odnosih. Ta interpretacija poudarja predvsem pozitiv- 


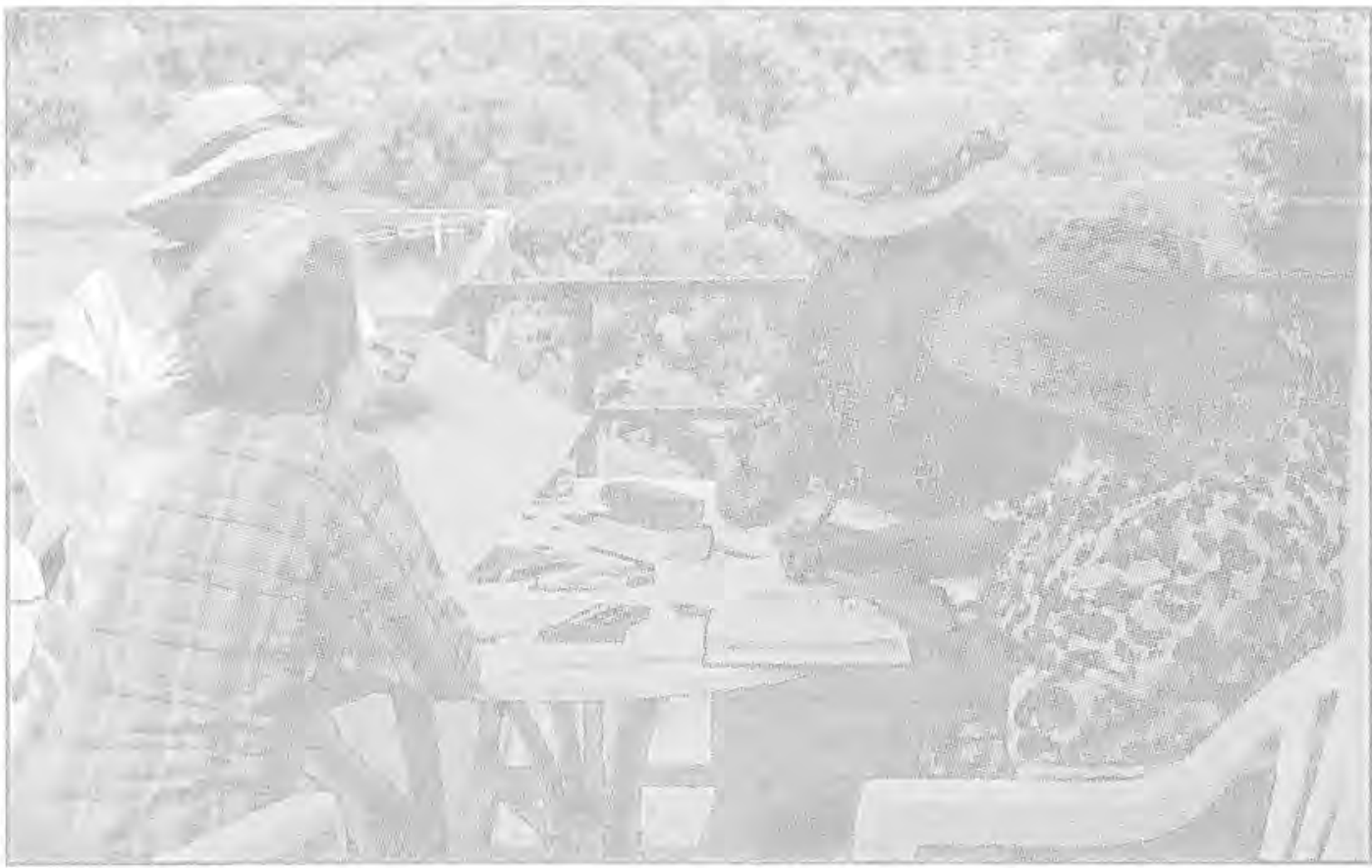

ne strani socialnega kapitala, raven analize pa je skupnost.

Druga interpretacija socialnega kapitala je reakcija na normativno-funkcionalistične razlage, ki si s socialnim kapitalom prizadevajo krepiti družbeno ureditev, ne da bi se vprašale o njeni pravičnosti. Socialni kapital je z vidika kritične teorije družbe (Bourdieu) mehanizem za reprodukcijo nepravične družbene ureditve. Bourdieujev koncept socialnega kapitala v ospredje postavlja koristi, ki jih ima posameznik od vključenosti $\mathrm{v}$ skupino ali širše omrežje medosebnih odnosov. V tej interpretaciji je poudarek na obsegu in strukturi socialnega kapitala posameznikov, raven analize je torej posameznik. V analizah so pogosto poudarjene zlasti negativne, temne strani socialnega kapitala.

\section{Normativno funkcionalistične opredelitve socialnega kapitala}

Coleman, ki je verjetno izvirni tvorec pojma socialni kapital, je pojem opredelil kot strukturo odnosov, ki ljudem omogoča, da dosegajo skupne cilje (Coleman, 1988). Izraža se $\mathrm{v}$ obveznostih in pričakovanjih, sposobnosti zbiranja informacij in $v$ socialnih normah, povezanih s sankcijami. To so po Colemanu tudi tri oblike socialnega kapitala. Prva oblika obravnava raven zaupanja, ki obstaja v socialnem okolju, in dejanski obseg obveznosti.

Socialni kapital je večji tam, kjer ljudje zaupajo drug drugemu in kjer se to zaupanje izraža $\mathrm{z}$ medsebojnim sprejemanjem obveznosti.

Kot primer takšne oblike socialnega kapitala Coleman navaja egiptovske tržnice, kjer si sosedski trgovci pomagajo s sposojanjem denarja, ne da bi pri tem sklepali uradne pogodbe. Druga oblika socialnega kapitala se nanaša na informacijske kanale. Coleman kot primer navaja univerzo, kjer socialni kapital vzdržujejo kolegi, ki si izmenjujejo ideje in informacije. Tretjo obliko socialnega kapitala 
tvorijo norme in sankcije, ki ljudi spodbujajo ali ovirajo pri delu za skupno korist, pri tem pa se odrekajo neposrednim osebnim koristim. Po opredelitvi Colemana je socialni kapital javna dobrina, ki se, $\mathrm{v}$ nasprotju $\mathrm{z}$ ekonomskim kapitalom, $\mathrm{z}$ uporabo povečuje, $\mathrm{z}$ neuporabo pa zmanjšuje.

\section{Socialni kapital je javna dobrina.}

Učinke socialnega kapitala na ustvarjanje človeškega kapitala je Coleman preučeval na ravni družine in lokalne

skupnosti. Družinski izvor ima pomembno vlogo pri izobraževalnih dosežkih; najprej v povezavi s finančnim kapitalom-denarjem, ki zagotavlja možnosti za študij (študijski prostor, pripomočki za učenje itd.), potem pa tudi v povezavi s človeškim kapitalom, ki se meri s stopnjo dosežene izobrazbe staršev in z njihovim vplivom na otrokovo kognitivno okolje. Temu Coleman doda socialni kapital, ki ga opredeli kot odnos med starši in otroki. Toda pri tem nima $\mathrm{v}$ mislih emocionalnega odnosa, temveč bolj neposredna prizadevanja staršev, ki jih usmerijo $v$ učenje svojih otrok. Coleman pojasnjuje, da visoko izobraženim staršem pogosto ne uspe spremeniti svojega človeškega kapitala v socialni kapital, in sicer zato, ker socialnega kapitala ne vgradijo $v$ svoje starševske odnose. Socialni kapital na ravni skupnosti pomeni vzajemno sodelovanje staršev na osnovi skupnih norm in njihove tesnejše stike $\mathrm{z}$ institucijami $\mathrm{v}$ skupnosti. Nizek je v okoljih, kjer se družine pogosto selijo in kjer je malo socialnih stikov med odraslimi člani skupnosti. To se lahko zgodi tudi tam, kjer je veliko človeškega in finančnega kapitala.

Coleman je mnenja, da so bile družbene strukturne razmere (to so predvsem notranje povezane družine in lokalne skupnosti), ki premagujejo probleme oskrbovanja s socialnim kapitalom kot javno dobrino, boljše $\mathrm{v}$ preteklosti kot $\mathrm{v}$ sedanjem času. Akterji, ki generirajo socialni kapital, imajo od tega le manjše koristi, in to dejstvo pojasnjuje podinvestiranost $\mathrm{v}$ socialni kapital. Coleman pri tem opozarja, da lahko kot posledico slabše oskrbe s socialnim kapitalom kot javno dobrino pričakujemo tudi upadanje človeškega kapitala.

Putnam je socialni kapital opredelil kot potezo socialnega življenja, kot so mreže, norme in zaupanje, ki udeležencem omogoča učinkovitejše vzajemno delovanje, da bi dosegli skupne cilje (Putnam, 1993). Trdil je, da lahko socialni kapital (oz. "družbena korist"), ki temelji na medsebojni povezanosti, zaupanju in nesebični pomoči med ljudmi, $v$ vseh družbah spodbuja gospodarsko in družbeno življenje, hkrati pa ustvarja takšno ozračje, $v$ katerem se je $z$ družbenimi, političnimi in gospodarskimi problemi laže spopadati in jih tudi laže reševati.

Putnamove trditve so podobne Colemanovim, saj sta oba prepričana, da je socialni kapital

Putnam je na osnovi obsežne, longitudinalne raziskave ugotovil, da se socialni kapital v ZDA nevarno zmanjšuje (Putnam, 1993). Svoje trditve je podkrepil z empiričnimi podatki o tem, koliko so Američani zaupali vladi v letih 1965,1975 in 1985 . V šestdesetih letih je kar 75 odstotkov Američanov zaupalo vladi in njenim odločitvam, $v$ začetku devetdesetih let pa le še 20 odstotkov. Toda v nadaljnjih analizah je Putnam ugotovil, da se mnogi državljani niso odtujili le od politike, marveč tudi od drugih, s politiko nepovezanih področij družbenega življenja (Putnam, 1995), Tako se je izredno skrčilo ělanstvo v večini prostovoljnih društev, saj so organizacije civilne družbe sčasoma izgubile kar 60 odstotkov aktivnih članov in prostovoljcev. Po njegovem mnenju je še bolj zaskrbljujoče dejstvo, da kar dve tretjini Američanov trdi, da ljudem ne zaupajo. 
koristen za skupnost in posameznika ter da so vzajemnost, zaupanje in horizontalne mreže temeljni elementi vzpostavljanja in vzdrževanja socialnega kapitala, Oba sta zelo jasna glede normativne vsebine svoje konceptualizacije. Poudarki so sicer različni, s tem da Putnam išče načine, kako bi revitaliziral politično zdravje ameriške družbe, Coleman pa pojasnjuje učinke socialnih odnosov, toda oba dajeta prednost normam in sankcijam za tiste, ki ne prispevajo njihovega deleža v skupno korist. Prav tako je pri obeh jasno pristajanje na kolektìvne vrednote.

Putnamove analize socialnega kapitala je naprej razvil Fukuyama (1995). Ugotovil je, da se socialni kapital vzpostavi šele, ko člani skupine zaupajo drug drugemu. Socialni kapital se najpogosteje generira v prostovoljnih skupinah in organizacijah, in sicer na osnovi skupnih pravil in norm, ki spodbujajo ali celo pogojujejo sodelovanje. Če imajo ljudje sposobnost, da zaupajo drugim ljudem, zaupanje generira socialni kapital, v nadaljevanju pa socialni kapital oplemeniti finančni kapital, skratka, vpliva na gospodarsko blaginjo države.

Idejo socialnega kapitala je v okviru komunitarizma razvil Etzioni (1995), Načela komunitarizma temeljijo na prepričanju, da naj bi večino socialnih storitev zagotavljale in tudi financirale lokalne skupnosti, država pa naj bi to odgovornost prevzela le, če je očitno, da lokalne skupnosti ne morejo teh storitev učinkovito zagotavljati. Poudarek je na revitalizaciji lokalnih skupnosti v smislu ozavedenja o pomenu odgovornosti in civilnih vrednot kot podlage za skupnostno življenje. Čeprav Etzioni ne uporablja jezika socialnega kapitala, temveč bolj jezik komunitarizma, je očitno, da so njegove ideje zelo blizu Colmanu in Putnamu, zlasti ko poudarja socialne odnose kot ključ za generiranje človeškega in fizičnega kapitala. Vsem trem je skupno tudi pripisovanje krivde tistim skupnostim, ki jim ne uspe generirati dovolj socialnega kapitala, saj naj bi le $\mathrm{z}$ njim vzdrževale svojo gospodarsko rast.

Med delno presežene normativno-funkcionalistične interpretacije lahko uvrstimo definicijo OECD. Socialni kapital opredeljuje kot mreže, skupne norme, vrednote in razumevanje, ki spodbujajo sodelovanje $\mathrm{v}$ skupinah in med njimi (OECD, 2001, str, 41). Pri tem je poudarek na možnosti soobstoja skupnih in različnih vrednot ter norm, kar v razmerah tolerance ne

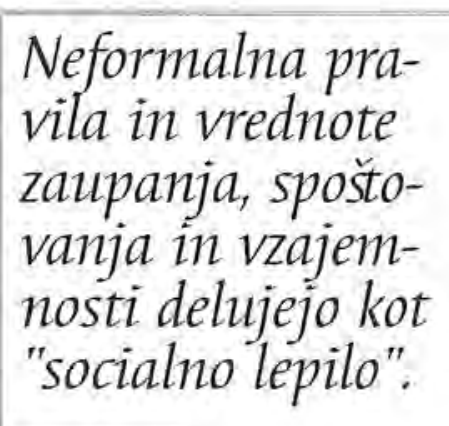
zmanjšuje sodelovanja. Dialog in vzajemno razumevanje, ki temelji na toleranci različnih kultur in prepričanj, sta pomembni dimenziji socialnega kapitala, ta pa krepi socialno kohezijo.

\section{Socialni kapital $\mathrm{z}$ vidika kritične teorije družbe}

$\mathrm{V}$ primerjavi $\mathrm{z}$ navedenimi koncepti lahko $\mathrm{v}$ okviru kritične teorije družbe zasledimo popolnoma nasprotno interpretacijo socialnega kapitala. Kritična teorija socialnega kapitala ne interpretira kot benigno entiteto, s katero se ustvarjata socialna harmonija in ekonomska prosperiteta za vse. Določeni socialni sloji ali

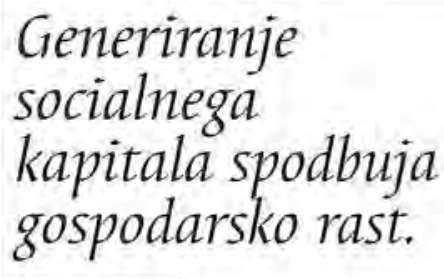
socialnega kapitala spor kapitala spodbuja gospodarsko rast.

skupine lahko, še zlasti v razmerah naraščajoče tekmovalnosti, okrepijo svoj socialni kapital, da bi zadržali dominantni položaj v družbi (Brown, 1995). Zaradi tega se socialni kapital kaže kot nepravičen mehanizem, ki ga srednji in višji razred uporabljata, da bi zavarovala svoje privilegije. Socialni kapital je tako videti kot maligna sila, ki je razgaljena $v$ retoriki interesov večje enakosti.

Bourdieu (1979) je prepričan, da sta kulturni 
in socialni kapital, enako kot ekonomski kapital, pomembna za reprodukcijo neenakih in nepravičnih socialnih odnosov. To je popolnoma nasprotno Etzionovi trditvi, da je socialni kapital osnova pravične družbe. Bourdieu trdi, da enakost možnosti prispeva $k$ produkciji neenakih rezultatov: čeprav imajo otroci na začetku šolanja enake možnosti, so od začetka neenako "opremljeni" za tekmovanje drug z drugim. Tako imajo otroci, ki izhajajo iz srednjega razreda, že na začetku šolanja habitus, uglašen s pričakovanji in kulturo šole, drugi otroci v tem svetu pa so zbegani, saj se ta zelo razlikuje od njihovega domačega okolja. Celo če so otroci $\mathrm{z}$ delavskim poreklom akademsko uspešni, zaradi pomanjkanja ustreznega socialnega kapitala doživijo nadaljnje ovire, ko se zaposlijo. Delodajalci namreč pogosto enake akademske kvalifikacije zelo različno vrednotijo. Pri tem ima pomembno vlogo ekonomski in socialni kapital družine, iz katere imetnik akademske kvalifikacije izhaja. V zvezi s tem Lister kritizira prevladujoči premik od diskurza revščine $\mathrm{k}$ diskurzu socialne vključenosti in od enakosti rezultatov $k$ enakosti možnosti (Lister, 1998). Sprašuje se, ali je resnično možno doseči večjo socialno vključenost brez doseganja večje enakosti, torej brez sprememb v strukturnih razmerjih družbe. Avtorica meni, da se teorija socialnega kapitala ne sprašuje o enakosti, temveč da zamaskirana $v$ jeziku komunitarizma in socialne vključenosti namenja pozornost zlasti socialnim odnosom, nujnim za generiranje človeškega kapitala.

Bourdieu trdi, da je podlaga za pridobitev socialnega kapitala obstoj ekonomskega, pa tudi kulturnega in političnega kapitala. Ugotavlja, da med temi vrstami kapitala prihaja do medsebojnih preoblikovanj in spreminjanja (Bourdieu, 1986). Vsak posameznik ima določeno zalogo socialnega kapitala, toda nekatere oblike tega kapitala je laže spremeniti in prenašati $v$ druge vrste kapita-
Obseg posameznikovega socialnega kapitala je odvisen od širine njegove socialne mreže, pa tudi od drugih vrst kapitalov, ki so mu na voljo. Socialni kapital je celota dejanskih in potencialnih virov, povezanih s posestjo bolj ali manj trajne mreže odnosov medsebojnega poznavanja in pripoznavanja (Nastran Ule, 2000, str. 291). Posameznik pride do socialnega kapitala $\mathrm{z}$ zavestnimi in nezavednimi investicijami $v$ socialne odnose, ki prej ali slej obljubljajo neko neposredno korist. Za rast in reprodukcijo socialnega kapitala je pomembno stalno delo $\mathrm{v}$ zvezi $\mathrm{z}$ odnosi $\mathrm{v}$ obliki nenehnih izmenjav ter medsebojnih priznavanj. Sodobne socialne mreže predelujejo velike količine vseh vrst kapitala in zahtevajo nenehne investicije $v$ zvezi $z$ nepretrganim odnosnim delom.

lov, npr. v ekonomski ali kulturni kapital, kot druge.

Povezanost med socialnim kapitalom in socialno neenakostjo $\mathrm{v}$ družbi je empirično preverjal Hall in ugotovil, da pripadniki srednjega razreda v svojem življenju akumulirajo več socialnega kapitala, saj se pogosteje vključujejo v različna društva in široke socialne mreže kot pripadniki delavskega razreda, ki so običajno člani manjšega števila društev (OECD, 2001, str. 56). Willms, ki je preučeval vpliv socialnega kapitala na izobraževalne dosežke in pismenost prebivalstva, je na podlagi empiričnih podatkov dokazal, da posamezniki iz revnejših družin (ki običajno Živijo v revnejših skupnostih) dosegajo slabše izobraževalne rezultate in so manj pismeni kot pripadniki skupnosti $\mathrm{z}$ veliko zalogo socialnega in kulturnega kapitala (OECD, 2001, str. 57).

Novejše analize opozarjajo na negativne plati, temne strani socialnega kapitala. Te so lahko podlaga socialnega izključevanja 


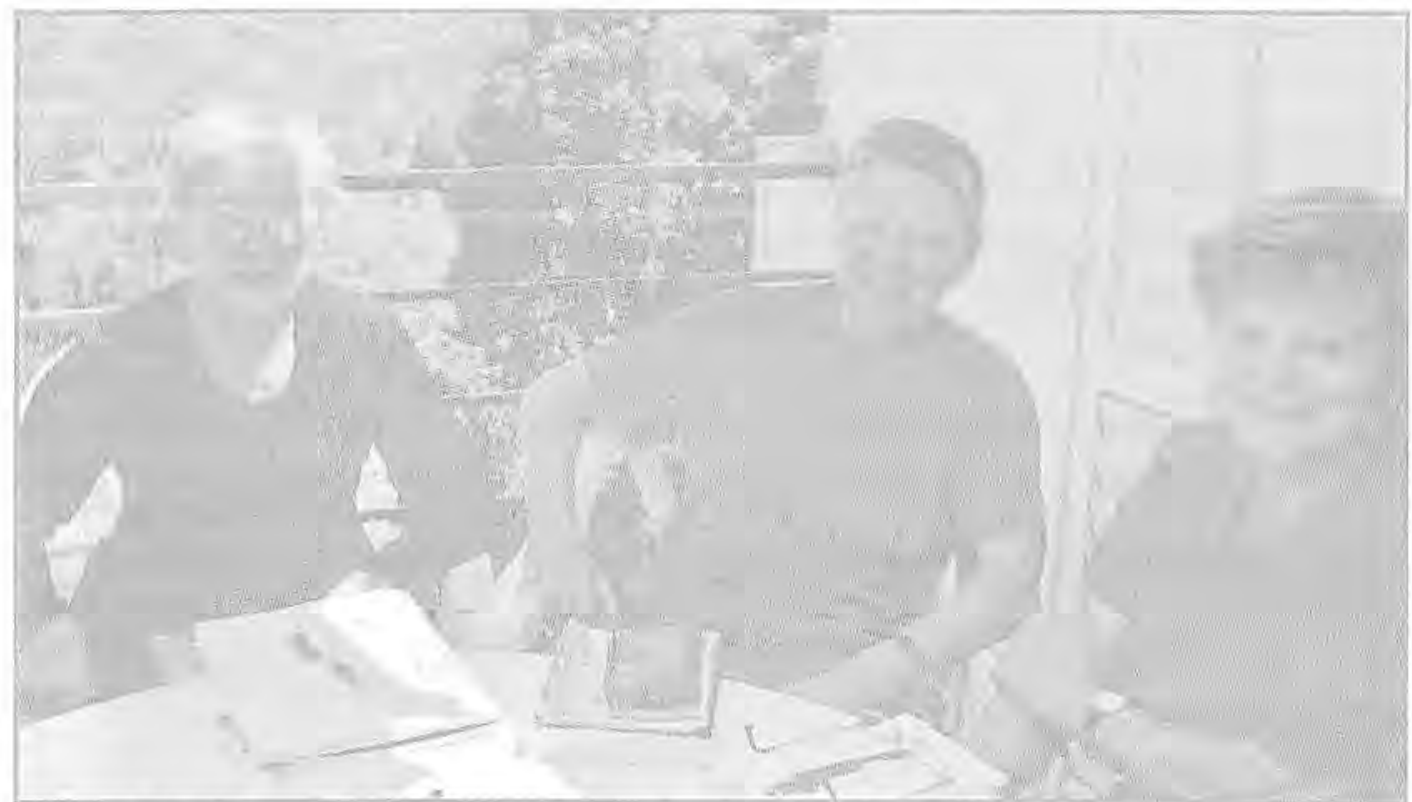

(Kanjuo Mrčela, 2001). Vsak socialni kapital in vsaka civilna družba namreč še ne prinašata le družbeno pozitivnih učinkov, kot so integracije, socialni stiki, pridobivanje informacij itn. (Hanžek, Gregorčič, 2001). Med negativne plati socialnega kapitala lahko uvrstimo zaprtost tesno povezanih socialnih skupin, kot so preprodajalci drog, politično in religiozno ekstremne skupine, mafijske združbe ali teroristične skupine, ki premorejo visoko raven notranjega zaupanja in reciprocitete, vendar navzven delujejo socialno destruktivno, saj so običajno netolerantne in celo nasilne. V teh primerih socialni kapital deluje razdiralno, ker ga ena skupina uporabi proti drugi skupini ali širši skupnosti.

Negativni socialni kapital lahko opazimo, kadar posamezniki ali skupine zaradi lastnih privilegijev izkoristijo socialne mreže za dostop do pomembnih informacij in vpliva, $s$ tem da izključijo druge. V razmeroma homogenih skupinah je običajno visoka stopnja zaupanja in sodelovanja, toda takšne skupine imajo pogosto nizko stopnjo zaupanja in sodelovanja s preostalo družbo. Zato so lahko določene oblike izključujočega povezovanja (na primer v okviru družinske, sorodstvene, etnične skupnosti ali zaprtih prijateljskih krogov) ovira socialne kohezije. Socialni kapital je lahko uporabljen tudi kot dokazovanje nujnosti vračanja $\mathrm{k}$ predmodernim oblikam sodelovanja-utemeljenim na tradicionalnih vrednotah in socialnih institucijah, kot sta patriarhalna družina ali cerkev (Kanjuo Mrčela, 2001). Retorika neoliberalnih politik na podlagi socialnega kapitala upravičuje zmanjševanje vloge in odgovornosti države ter odgovornost prenaša na lokalno in individualno raven (takšen primer je Etzionijev komunitarizem).

Predstavniki kritične teorije družbe opozarjajo, da imajo lahko koncepti socialnega kapitala, ki so jih razvili Putnam, Coleman in Etzioni, negativne implikacije za marginalizirane posameznike ali skupine (npr. bolni, starejši, ženske, etnične manjšine itd.). V teh primerih socialni kapital diskriminira drugačnost. Če sta namreč nujni pogoj za generiranje socialnega kapitala zaupanje in reciprociteta, so mnogi marginalizirani posamezniki ali skupine izločeni iz tega pro- 
cesa, ker nimajo dovolj osebnih, ekonomskih in kulturnih potencialov, s katerimi bi lahko skupnosti v enaki meri vrnili pomoč, ki jim jo daje. Dostop do socialnih pravic vključuje podobne vrste odgovornosti za vse. To ima negativne posledice za tiste, ki so morda

Raven socialnega kapitala vpliva na bogastvo družbe.

manj sposobni izpolnjevati njihove socialne obveze (Riddell, Baron, Wilson, 1999). Sankcija za tiste, ki odstopajo od vzpostavljenih socialnih norm, je $v$ tem primeru lahko povečana izolacija oz, socialna izključenost.

\section{ODNOS MED SOCIALNIM IN ČLOVEŠKIM KAPITALOM}

Koncepti socialnega kapitala, zlasti tisti, ki so jih razvili Coleman, Putnam in Fukuyama, izhajajo iz domneve, da teorija človeškega kapitala nezadostno pojasnjuje, zakaj so nekateri posamezniki in družbe bogatejši od drugih. Zlasti Coleman in Putnam problematizirata pojem človeškega kapitala, kadar je ločen od širših socialnih odnosov. Odklanjata individualizem in domnevno racionalnost pristopov ortodoksnega človeškega kapitala.

Becker, ki je $v$ šestdesetih letih razvil koncept človeškega kapitala, je izhajal iz domneve, da je investicija $v$ izobraževanje prav tako pomemben dejavnik ekonomske rasti kot investicija v fizični obratni material in opremo tovarn (Becker, 1967). Beckerjeva različica človeškega kapitala predpostavlja, da se posamezniki izobražujejo zaradi osebnih ekonomskih koristi. Zaradi ekonomskih razlogov tudi država investira v izobraževanje posameznikov $\mathrm{v}$ skladu $\mathrm{z}$ njihovimi sposobnostmi povratnega donosa $\mathrm{v}$ gospodarstvo države. Pojem človeškega kapitala razlike v dohodkih pojasnjuje kot donosnost človeškega kapitala, ki se meri s povezanostjo med številom let formalnega izobraževanja ali številom kvalifikacij in zaslužki posameznikov. Ekonomisti ugotavljajo, da so donosi formalnega izobraževanja visoki, zato revščino pojasnjujejo kot pomanjkanje človeškega kapitala.

Putnam se je $v$ svojih raziskavah osredotočil na razmerje med stopnjo socialnega kapitala $\mathrm{v}$ civilni družbi in njenim človeškim ter ekonomskim kapitalom. Prepričan je bil, da je socialni kapital za gospodarsko rast države lahko celo pomembnejši kot fizični ali človeški kapital (Putnam, 1993, str. 183). Še več, trdil je, da socialni kapital generira človeški kapital in gospodarski razcvet, in ne nasprotno. To trditev je utemeljil $\mathrm{z}$ merjenjem so-

"Socialni kapital znotraj družine, ki zagotavlja otrokom dostop do človeškega kapitala odraslih, je odvisen od fizične prisotnosti odraslih $v$ družini in od pozornosti, ki jo odrasli namenjajo otrokom. Fizično odsotnost bi lahko opisali kot strukturni primanjkljaj v družinskem socialnem kapitalu. Najbolj izrazit element strukturnega deficita $v$ modernih družinah je enostarševska družina." (Coleman, 1988, str. 11.) Zaradi naraščanja števila enostarševskih družin in števila družin, v katerih sta oba starša zaposlena, je Coleman napovedoval, da se bo $v$ naslednjih generacijah zmanjševala količina človeškega kapitala. Po njegovem mnenju $v$ sodobni družbi najbolj uspe tisti, ki imajo inherentno superiornost $v$ socialnem kapitalu. To vodi $\mathrm{v}$ oblikovanje človeškega kapitala in s tem do fizičnega in ekonomskega kapitala, skratka, do uspeha. Colemanove trditve so problematične, saj statistika kaže, da raven dosežene izobrazbe prebivalstva v razvitem svetu nenehno narašča in da so izobraževalni dosežki otrok slabši zlasti v družinah, v katerih sta oba starša nezaposlena (Riddell, Baron, Wilson, 1999). 
cialnega kapitala v severni in južni Italiji. $\mathrm{Na}$ gospodarsko razvitejšem severu je izmeril večjo gostoto civilnih asociacij (tj. horizontalnih povezav, ki temeljijo na medsebojni odgovornosti in etiki solidarnosti ter altruizma) kot na manj razvitem jugu. Regije so $v$ severni Italiji uspešne v vzdrževanju zalog socialnega kapitala, kot so zaupanje, norme in mreže, južna Italija pa je postala žrtev kulture, pri čemer imata individualizem in lojalnost družini prednost pred širšo civilno odgovornostjo. Mreže v južni Italiji so predvsem vertikalne in temeljijo na moči ter spoštovanju, mreže v severni Italiji pa so predvsem horizontalne, temeljijo pa na demokratičnem sodelovanju enakih.

Za Colemana je pojem socialnega kapitala komplementaren pojmu človeškega kapitala, saj pomaga pojasniti variacije na ravneh človeškega kapitala $v$ določeni družbi. Coleman je opozarjal, da lahko skupnosti, ki sprotno ne obnavljajo socialnega kapitala, ogrozijo zalogo svojega človeškega kapitala (Coleman, 1988). To nevarnost je ponazoril s primerom družine srednjega razreda. Starši se ukvarjajo predvsem s poklicno kariero in svojim otrokom namenjajo premalo pozornosti. Slednjim zato morda ne bo uspelo vzdrževati visoke ravni človeškega kapitala svojih staršev v prihodnjih generacijah.

Schuller in Field (1998) menita, da razmerje med človeškim kapitalom in socialnim kapitalom ni nujno antagonistično, toda hkrati poudarjata pomembne razlike med obema pojmoma:

- človeški kapital je osredotočen na posameznika, socialni kapital pa na mreže in odnose;

- človeški kapital izhaja iz ekonomske racionalnosti in transparentnosti informacij, socialni kapital pa iz socialno zasnovanih vrednot in norm;

- človeški kapital se meri s številom let šolanja ali s številom kvalifikacij, socialni

kapital pa z močjo vzajemnih obvez in civilnega delovanja;

- človeški kapital meri vlaganje v izobraževanje s prihodki (plačami), socialni kapital pa s kakovostjo življenja.

Adam s sodelavci ugotavlja, da je socialni kapital katalizator, ki spravlja v obtok človeški kapital (Adam in drugi, 2001, str. 41). Poudarek je na kakovosti in intenziteti medosebnih odnosov, na kultiviranju teh odno-

Socialni kapital omogoča kroženje znanja. sov, na podlagi katerih se prelivajo informacije, medsebojna pomoč, nove ideje. Tako se ohranjata in krožita znanje ter intelektualni in kulturni kapital.

Novejše raziskave potrjujejo, da se človeški in

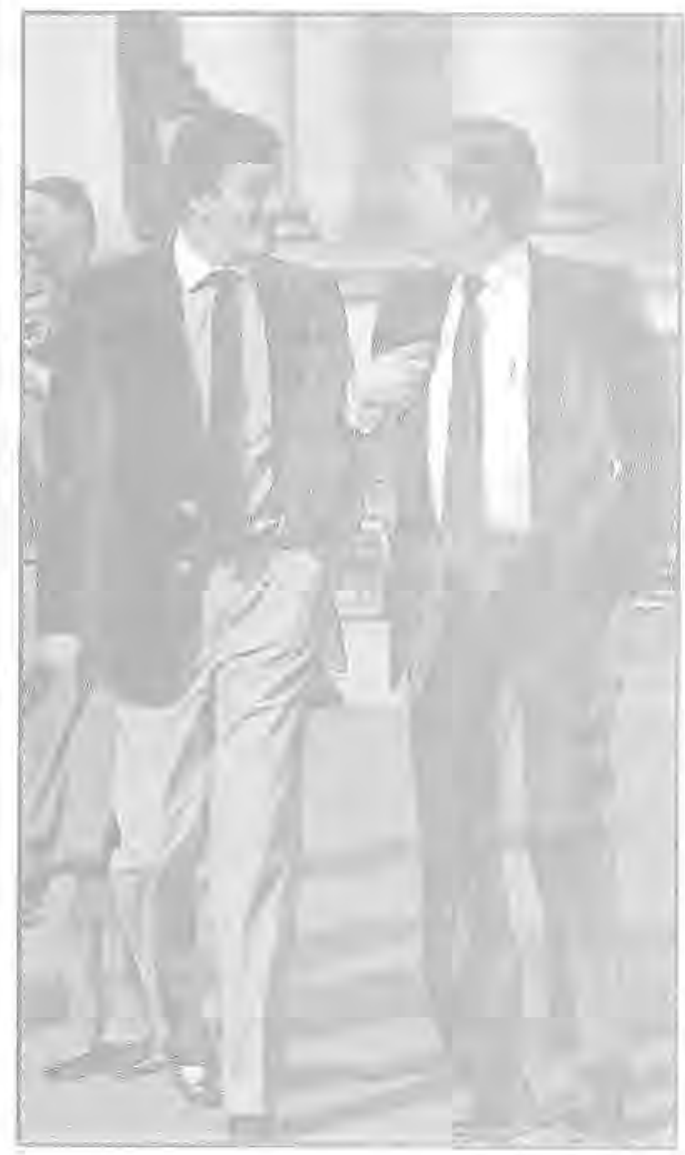


socialni kapital lahko med seboj krepita, kajti med civilnim delovanjem in zaupanjem na eni strani ter stopnjo dosežene izobrazbe na drugi strani obstaja pozitivna povezava (OECD, 2001). $Z$ dosedanjimi raziskavami pa ni mogoče potrditi močne povezanosti med socialnim kapitalom in ekonomsko rastjo. Na to zvezo namreč zelo močno vplivajo razliěni zgodovinski, kulturni, institucionalni in družbeni dejavniki.

Kritiki koncepta človeškega kapitala opozarjajo, da donosi, povezani $\mathrm{z}$ izobraževanjem, dejansko izhajajo iz drugih virov, npr. izobraževanje lahko deluje zgolj kot filter ali "dimna zavesa". Tako ima lahko pomembno vlogo v povezavi med izobrazbo in zaslužki tudi družinski izvor ali na primer posameznikove prirojene sposobnosti. Posameznikova izobrazba seveda ni nujno povezana $\mathrm{z}$ njegovimi višjimi donosi; prav gotovo pa se ne rezultira $v$ višjjih iztržkih celotne družbe (Riddell, Baron, Wilson, 1999). Ekspanzija izobraževanja povečuje tekmovalnost na trgu delovne sile, kjer je izobrazba sicer nujna, vsekakor pa več ne zagotavlja visokega položaja in visokih zaslužkov. Izobrazba postaja sredstvo selekcije na trgu dela, nikakor pa ne pomeni garancije za visok zaslužek.

Socialni kapital spodbuja udeležbo $\checkmark$ kolektivnih akcijah.
$\mathrm{Z}$ andragoškega vidika se omejenost koncepta človeškega kapitala kaže v tem, da pojem ne upošteva razliěnih oblik neformalnega izobraževanja odraslih, ki jih ekonomisti obravnavajo predvsem kot obliko porabe prostega časa. Po njihovem mnenju takšne oblike izobraževanja niso relevantne $\mathrm{za}$ produktivnost in konkurenčnost (Schuller, Field, 1998). Seveda je $v$ razpravah, $v$ katerih prevladuje jezik investiranja, težko dokazovati upravičenost in pomembnost številnih vrst ter oblik učenja, za katere ne moremo dokazati hitrega in vidnega denarnega povračila, torej neposredne vrednosti vložene investicije.

$\mathrm{V}$ formalnem izobraževanju je poudarek na individualnih dosežkih in tekmovalnosti, ki poteka na škodo osebnih odnosov in komunikacije, pri tem pa se zmanjšuje socialna solidarnost. Človeški kapital je torej osredotočen na individualne izobraževalne dosežke posameznikov, pri tem pa ne upošteva širšega socialnega konteksta, znotraj katerega poteka večina učenja. Pojem torej ignorira osebne in institucionalne odnose, ki dejansko sestavljajo kanale, skozi katere poteka učenje. In ravno to področje odnosov je predmet analiz socialnega $\mathrm{ka}$ pitala na področju izobraževanja.

Če se torej človeški kapital akumulira neodvisno od socialnih kontekstov, bo imel v najboljšem primeru zelo omejeno socialno in ekonomsko vrednost. Socialni kapital pa omogoča, da se različna področja znanja ali spretnosti posameznikov povezujejo in dopolnjujejo. Torej lahko vpliva na večjo vrednost človeškega kapitala.

\section{KJE NASTAJA SOCIALNI KAPITAL?}

Socialni kapital se lahko ustvarja in razvija v družinah, izobraževalnih institucijah, lokalnih skupnostih, civilni družbi, podjetjih in javnem sektorju (OECD, 2001). Največjo vlogo pri nastajanju socialnega kapitala naj bi imela civilna družba oziroma tako imenovano intermediarno področje, ki vključuje vsa formalna ali neformalna prostovoljna združenja, skupine, društva in socialna omrežja v prostoru med družino (zasebno sfero) in državo (javno sfero). Za organizacije na intermediarnem področju je značilno, da so nevladne, formalno ustanovljene, neprofitno distributivne, samostojno vodene in upravljane ter da vključujejo določeno količino prostovoljnega dela (Salamon, Anheier, 1992). Berger in Luckmann (1999) ponujata svoj 
koncept intermediarnih institucij, ki posredujejo med posameznikom ter družbenimi makrosistemi in so imunski sistem družbe, $\mathrm{ki}$ naj bi omilil krizo smisla $\mathrm{v}$ sodobnih družbah.

Socialni kapital naj bi bil nujni temeljni pogoj za ustanavljanje intermediarnih struktur, ki krepijo tudi socialni kapital (Adam, 1998). Med socialnim kapitalom in intermediarnim področjem torej obstaja pozitivna zveza. Socialni kapital namreč omogoča in spodbuja udeležbo v kolektivni akciji, in sicer s ciljem, da se oblikujejo in ohranijo zveze in mreže na intermediarnem področju.

Na potencial socialnega kapitala v družbi po Putnamu in številnih drugih avtorjih še zlasti pomembno vplivajo prostovoljne organizacije (Hanžek, Gregorčič, 2001). Putnam poudarja pomen različnih vrst društev (športni klubi, kooperative, društva za vzajemno pomoč, kulturna društva, sindikati itd.), v katerih udeleženci akumulirajo socialni kapital in kolektivno delujejo na način, ki ima pozitivni vpliv na blaginjo in produktivnost celotne skupnosti. Putnam je na podlagi analiz socialnega kapitala pojasnil razlike $v$ ekonomskem ter političnem delovanju med italijanskimi regijami in ugotovil, da socialni kapital ni pomemben le za nastanek civilnih združenj, temveč tudi za učinkovito delovanje državnih institucij. Če so te institucije demokratične in odzivne, spodbujajo in podpirajo oblikovanje socialnega kapitala, ta pa bo nasprotno, izboljšal njihovo delo. Adam (1998) v zvezi s tem opozarja na aktualnost Durkheimove trditve, da lahko razvoj v smeri avtonomnosti in dezintegracije učinkovito preprečimo $\mathrm{z}$ ustvarjanjem vezi med državljani in državo.

$\mathrm{Na}$ osnovi preučevanja razmer $v$ Italiji je Putnam postavil tezo, da so različne oblike državljanske aktivnosti med seboj povezane; t.j. člani društev se bolj pogosto udeležujejo volitev kot pasivni državljani, ki berejo samo časopise. V takšnem članstvu je posebna vrsta izobraževanja. Ker se posamezniki v prostovoljnih društvih učijo, kako se vključiti $\mathrm{v}$ razprave $\mathrm{z}$ drugimi, $\mathrm{ki}$ imajo pogosto nasprotna stališča, je Putnam te organizacije označil za "šole demokracije". Putnamovemu razumevanju mreže civilnega delovanja kot bistvene oblike socialnega kapitala je blizu britansko pojmovanje aktivnega državljanstva kot civilnega delovanja $\mathrm{v}$ različnih neformalnih in prostovoljnih organizacijah, ki po-

Izobraževanje ima pomembno vlogo $v$ prostovoljnih organizacijah, saj se med skupnim delovanjem razvijejo nova znanja, novo vedenje in nove spretnosti. Posamezniki si različne spretnosti in znanja, pomembna za njihovo delovanje $v$ društvih, običajno pridobijo na podlagi izkušenj in $z$ neformahim učenjem. Učijo se drug od drugega, pogosto se učenja sploh ne zavedajo. Razviti prostovoljni sektor ponuja različne vrste izobraževanja odraslih, in sicer organizirane tečaje, pisne vire, učenje $\mathrm{z}$ opazovanjem drugih prostovoljcev pri delu, strokovne nasvete mentorjev ali vodij prostovoljcev, razprave, ki vključujejo refleksije in učenje $\mathrm{z}$ delovanjem. Organizira tudi ponudbo izobraževanja za različne udeležence: prostovoljce, njihove mentorje in vodilne delavce, poleg tega tudi za potencialne prostovoljce in donatorje. Tudi izobraževanje za aktivno državljanstvo in demokratično politiko, ki zahteva civilne vrline, je uspešnejše, če državljani sodelujejo v različnih društvih in zvezah.

sameznike povezuje $\mathrm{v}$ njihovih lokalnih skupnostih (Benn, 2000).

Adam s sodelavci (2001, str. 89) ugotavlja, da je $v$ državah $z$ visoko stopnjo socialnega kapitala omrežje intermediativnih institucij aktivnejše in bolj zadovoljuje potrebe uporabnikov. To prav tako velja za organizacijo učenja, tudi zato, ker so neformalne oblike učenja čedalje pomembnejši vidik, formalno izobraževanje pa je le temelj, na katerem se znanje lahko gradi naprej. Pri tem lahko postavimo domnevo, da lahko socialni kapital vpliva na motiviranost odraslih za izobraževanje. Potencialne učinke socialnega kapitala na izobraževanje odraslih so potrdili 
rezultati raziskave, ki so jo $\mathrm{v}$ devetdesetih letih opravili na Japonskem (Comparative studies on lifelong learning policies, 1997). Empirični podatki so pokazali, da je pripravljenost za prostovoljno delo povečala interes odraslih za učenje. Tudi analize OECD kažejo, da je v državah in regijah $z$ visoko stopnjo zaupanja in civilnega delovanja opazna večja enakost glede pismenosti odraslih in dostopa do nadaljnjega izobraževanja (OECD, 2001, str. 56).

Pomemben potencial socialnega kapitala so tudi izobraževalne institucije, ki lahko spodbujajo sodelovanje in zagotavljajo "mesta druženja". Zlasti visokošolske institucije, organizacije za izobraževanje odraslih in različna društva lahko spodbudijo oblikovanje mrež, ki povezujejo različne sektorje učenja in prostovoljnih iniciativ. Regionalne ali lokalne učne mreže omogočajo pretok informacij in vzajemno učenje. Tiste izobraževalne institucije, ki razvijajo različne oblike vzajemnega učenja, skupinsko delo, odprtost do novih idej in kulturne različnosti, lahko spodbujajo naraščanje socialnega kapitala, ki premošča in povezuje različne skupine $v$ družbi. Vpliv tako usmerjenih izobraževalnih organizacij se lahko kaže v okolju, kjer delujejo. Lokalne

Socialni kapital se najveckrat meris stopnjo zaupanja $v$ institucije in posameznike. skupnosti in regije, ki imajo razvite lokalne mreže učenja, so potencialno bolj prožne in dinamične kot tiste, v katerih je učenje omejeno na posamezne izobraževalne institucije. $\mathrm{Za}$ tiste, $\mathrm{ki}$ se ukvarjajo s vprašanji izobraževanja za razvoj lokalne skupnosti, je lahko informativna Ahbejeva opredelitev lokalnih ali regionalnih vrst kapitala. Ta vrsta kapitala označuje prednosti posameznikov iz določene socialne regije pred konkurenti iz drugih socialnih regij pri pridobivanju in uporabi drugih vrst kapitala (Ahbe, 1998 v Nastran Ule, 2000). Prednosti se kažejo zlasti $v$ možnosti dostopa do izobražeyanja, razvijanju in vzdrževanju odnosov, poklicne kariere, $v$ možnostih in podpori, ki jih daje lokalno okolje za izrabljanje obstoječih in latentnih virov $v$ socialnem, kulturnem in ekonomskem kapitalu.

\section{MERJENJE SOCIALNEGA KAPITALA}

Metodološka orodja za merjenje socialnega kapitala so šibka točka analiz. Za zdaj je še veliko nerešenih vprašanj, povezanih $z$ ustreznostjo in veljavnostjo metodoloških pristopov ter kazalcev, s katerimi raziskovalci merijo socialni kapital oziroma stopnjo njegove akumulacije oz. erozije.

Raziskovalci socialni kapital največkrat merijo s stopnjo zaupanja in sodelovanja $v$ različnih družbenih skupinah oz. Z razširjenostjo nevladnih organizacij. Mere socialnega kapitala so lahko različne dimenzije, na primer mreže, vrednote in norme, stopnja izraženega zaupanja, članstvo $\mathrm{v}$ društvih ter obseg socialnih vezi. Socialni kapital lahko merimo kot neodvisno ali odvisno spremenljivko, npr. kot razlog za določene izobraževalne rezultate ali pa kot posledico določenih izobraževalnih dejavnosti. Putnam je v svojih longitudinalnih raziskavah socialni kapital meril $\mathrm{z}$ intenzitetami vključenosti $v$ skupnost, deležem sodelovanja na volitvah, vključenostjo v prostovoljno delo, pogostostjo neformalnega druženja (na primer obiskovanje prijateljev) in izraženo stopnjo medosebnega zaupanja. Svetovna banka meri socialni kapital $\mathrm{z}$ obsegom sodelovanja $v$ društvih in stopnjo zaupanja $v$ različne institucije ter posameznike (OECD, 2001).

Ena od oblik ugotavljanja prisotnosti socialnega kapitala poteka na podlagi merjenja socialnih disfunkcij (kot so delež kriminala, ločitev, zloraba drog, samomori, tožbe na 
sodiščih, izmikanje plačevanju davkov itn.) ali odsotnosti socialnega sodelovanja (Fukuyama, 1995). Pri tem je potrebna velika mera previdnosti, kajti za socialne zlome je vrsta različnih vzrokov in odsotnost socialnega kapitala je lahko le eden od potencialnih dejavnikov. Pri takšnih pristopih lahko tvegamo, da bodo posledice zamenjane $\mathrm{z}$ izvori pojava.

Pri naštetih kazalcih socialnega kapitala se pojavljajo številni problemi merjenja. Če vzamemo za primer zaupanje, je potrebno razlikovati med tem, ali ljudje zaupajo drugim ali pa so vredni zaupanja, torej so zanesljivi. Razlikujemo lahko vsaj med tremi vrstami zaupanja: medosebno zaupanje med člani družine, ožjimi sodelavci, prijatelji in sosedi, medosebno zaupanje med "tujci" in zaupanje $v$ javne in zasebne institucije (OECD, 2001). Merila zaupanja je torej potrebno interpretirati zelo previdno. Pri tem je potrebno razlikovati med dispozicijami posameznikov, da zaupajo drugim na splošno, ne glede na kontekst, in dispozicijami posameznikov, da zaupajo poznanim osebam, kar je seveda nekaj drugega, kot je zaupanje $v$ ljudi na splošno (razlikovati je torej potrebno med interpersonalnim zaupanjem med "domačimi" in "tujci").

Čeprav je med zaupanjem in civilnim delovanjem močna zveza, lahko visoka raven zaupanja na enem področju soobstaja $\mathrm{z}$ omejenim dometom delovanja ali zaupanja na drugem področju. Zaradi tega splošna merila, kot sta zaupanje ali civilno delovanje, ne zagotavljajo zanesljivih meril za ugotavljanje kakovosti socialnih odnosov na makro ravni. Merjenje splošne ravni zaupanja v družbi ima majhno pojasnjevalno vrednost, saj ne upošteva različnosti med deli populacije in vpliv socialno-ekonomskega položaja na obseg in kvaliteto socialnega kapitala.

Mednarodne podatke (npr. World Value
V zadnjem času postaja vsé pomembnejša analiza družbenih omrežij, saj se lahko socialni kapital izrazi z vzorci odnosov med sodelujočimi (Hlebec, Ferligoj, 1996). Primer novejše analize socialnega kapitala na podlagi merjenja osebnih vezi je pristop, osredotočen na egocentrične mreže predstavnikov slovenskih elit (Iglič, Rus, 2000). Vsak respondent je $v$ tej analizi obravnavan kot center mreže (ego), iz katerega segajo vezi do ljudi $\mathrm{v}$ njegovem socialnem krogu (alterji). Rezultat takega zbiranja relacijskih podatkov je popis socialne mreže vsakega respondenta posebej.

Survay) o obstoju socialnega kapitala je potrebno obravnavati še posebej previdno. Uporaba takšnih meril naj bi bila vedno povezana s kulturnim kontekstom, saj se lahko enaka vprašanja o zaupanju zelo razlikujejo med posameznimi državami. Socialni kapital je večdimenzionalni pojav, ki ga je $\mathrm{z}$ nekaj kazalci težko izmeriti. Za nobeno družbo ali državo ni mogoče izmeriti absolutne vrednosti socialnega kapitala, saj ni mogoče vključiti oziroma izključiti vseh dejavnikov, odnosov in vplivov, $\mathrm{ki}$ (so)oblikujejo (pozitivni/negativni) socialni kapital (Hanžek, Gregorčič, 2001). Zaradi tega tudi merila, kot so stopnja zaupanja, sodelovanje na volitvah ali članstvo $v$ društvih, ostajajo le približne in ne popolnoma validne mere socialnega kapitala.

Problemi primernih meril za ugotavljanje akumulacije ali erozije socialnega kapitala ostajajo nerešeni, toda glede na dejstvo, da je koncept socialnega kapitala uporaben za analize $v$ različnih disciplinah, lahko pričakujemo, da bodo raziskovalci in metodologi kmalu razvili izpopolnjena in veljavnejša metodološka orodja za njegovo merjenje, 


\section{VPLIV SOCIALNEGA KAPITALA NA IZOBRAŽEVANJE ODRASLIH V SLOVENIJI}

Raziskave o vplivu socialnega kapitala na izobraževanje odraslih v Sloveniji še nimamo. Toda če upoštevamo rezultate novejših analiz socialnega kapitala in podatke o funkcionalni pismenosti v Sloveniji, lahko domnevamo, da je takšen vpliv prisoten.

Iz podatkov in ocen zadnjega Poročila o človekovem razvoju - Slovenija 2000-2001

Slovenija razpolaga z majhno zalogo socialnega kapitala.
(Hanžek, Gregorčič, 2001) lahko vidimo, da imamo $v$ Sloveniji dokaj šibko razvito intermediarno področje in da smo država z majhno zalogo socialnega kapitala. V mednarodni primerjavi se je Slovenija glede na število članov prostovoljnih organizacij in opravljanja prostovoljnega dela leta 1992 uvrstila na dno lestvice med 174 državami. Čeprav se je od takrat članstvo povečalo skoraj za trikrat, še vedno ne dosegamo niti svetovnega povprečja iz leta 1992. Tudi po stopnji medosebnega zaupanja je Slovenija ena najslabše uvrščenih držav $v$ svetovnem in evropskem merilu. Čeprav se je v zadnjih letih stopnja zaupanja nekoliko izboljšala, Slovenija še vedno zaostaja za svetovnim povprečjem in povprečjem v EU iz leta 1992.
Za Slovenijo so torej značilni nizka stopnja socialnih stikov, nizka stopnja medosebnega zaupanja in zaupanja $v$ institucije, nemožnost participacije državljanov, neorganizirana, nepovezana in neangažirana civilna družba, maloštevilno članstvo in neintenzivno delo $\mathrm{v}$ prostovoljnih organizacijah, skratka, potencial socialnega kapitala je neizrabljen (Hanžek, Gregorčič, 2001). Po drugi strani pa je značilna visoka stopnja nestrpnosti in visok indeks etnocentrizma. Avtorji slovenskega poročila o človekovem razvoju ugotavljajo, da se družbena klima nagiba k delitvam, neenakosti, tekmovanju, privilegijem, nestrpnosti itn.
Stopnja medosebnega zaupanja je v Sloveniji najvišja $v$ družini. Toda ta vrsta zaupanja lahko pomeni potencial nezaupanja in zaprtost do drugih družbenih skupin in socialnega okolja oz. negativni socialni kapital. Medosebno zaupanje napoveduje tudi stopnjo zaupanja v (državne) institucije. Ta je bila po osamosvojitvi razmeroma visoka, toda $v$ osmih letih je ( $\mathrm{z}$ izjemo zaupanja $v$ izobraževalni sistem in tisk) izrazito upadla.

Primanjkljaji socialnega kapitala na intermediarnem področju se kažejo tudi $v$ pomanjkanju sodelovanja in zaupanja med društvi, saj med njimi pogosto prevladuje vzajemno nezanimanje, včasih pa se pojavljajo celo napetosti, konflikti in tekmovanje. Opazno je pomanjkanje horizontalnih zvez, mrež in nacionalne koordinacije podobnih društev in organizacij. Tudi med državnimi institucijami in intermediarnim področjem ni ustrezne povezave. Predpostavljamo lahko, da socialnega kapitala primajkuje tudi $\mathrm{v}$ slovenski politiki. To se kaže y slabši odzivnosti države na spremembe.

Po podatkih mednarodne raziskave o pismenosti odraslih, ki se je končala leta 1998, se Slovenija med 20 državami uvršča med države $\mathrm{z}$ visoko stopnjo funkcionalno nepismenega odraslega prebivalstva (Možina, 2000). Raziskovalci so ugotovili, da najvišje ravni pismenosti ne dosega niti 10 odstotkov odraslega prebivalstva, hkrati pa približno 70 odstotkov odraslega slovenskega prebivalstva ne obvladuje tistih znanj in spretnosti, ki so nujne za enakopravno udeležbo in opravljanje različnih vlog v sodobni informacijski družbi. Na funkcionalno pismenost odraslega prebivalstva najbolj vplivajo dejavniki, kot so izobrazba, starost, izobrazba staršev in zaposlitveni položaj. V različne oblike nadaljnjega izobraževanja po končanem šolanju se vključujejo tisti, ki so zaposleni in ki imajo visoko stopnjo dosežene 
izobrazbe, najmanj pa so vključene tiste družbene skupine, ki bi glede na pisne dosežke najbolj potrebovale dodatno izobraževanje (brezposelni, gospodinje, upokojenci, kmetje).

Pri tem lahko predpostavljamo, da je eden od pomembnejših dejavnikov, ki vplivajo na funkcionalno pismenost odraslega prebivalstva, tudi socialni kapital. Rezultati obeh mednarodnih raziskav kažejo, da je Slovenija država z nizko stopnjo zaupanja in civilnega delovanja, hkrati pa tudi država, za katero je značilna velika neenakost glede pismenosti odraslih in dostopa do nadaljnjega izobraževanja. Na osnovi obstoječih raziskav lahko domnevamo, da imajo primanjkljaje socialnega kapitala in funkcionalne pismenosti predvsem tiste deprivilegirane skupine slovenskih državljanov, ki imajo manj možnosti sodelovanja, vpliva in soodločanja na vseh ravneh družbe, prav tako pa imajo verjetno otežen dostop do uporabnih in koristnih informacij.

\section{SKLEPNE MISLI}

Kakšne so lahko implikacije te razprave za področje izobraževanja odraslih? Ker številne raziskave potrjujejo pozitivne potenciale socialnega kapitala, se $\mathrm{v}$ andragoški teoriji in praksi pojavljajo vprašanja, kot so Kakšne vrste institucionalnih odnosov bolj podpirajo učenje? Kakšne so vrste konteksta in kulture, ki spodbujajo komunikacijo in vzajemno učenje? S katerimi oblikami, organizacijami in mrežami učenja lahko povečamo zaloge socialnega kapitala v družbi?

$\mathrm{Z}$ uporabo koncepta socialnega kapitala lahko obogatimo in razširimo analiziranje in razumevanje številnih pojavov $v$ izobraževanju odraslih. Toda pri tem je potrebno opozoriti, da posamezni prispevki o izobraževanju odraslih vključujejo nekritično prevzemanje konceptov, ki se razvijajo v
Različni raziskovalci socialnega kapitala prihajajo do podobnih ugotovitev: večje zaloge socialnega kapitala na individualni in tudi na skupinski ravni imajo tisti, ki so bolj izobraženi (Hanžek, Gregorčič, 2001). Prizadevanja številnih izobraževalcev odraslih, da bi povečali število ljudi, ki bi se dejavno vključevali $v$ demokratično družbo, so deloma onemogočena, kajti čedalje jasneje postaja, da se $v$ formalno izobraževanje vkljuěuje le peščica odraslih, ki so že sicer dejavni v skupnosti, tisti, ki niso vključeni v organizacije civilne družbe, pa se ne vključujejo niti v izobraževanje (Benn, 2000). Izobraževalci odraslih torej ne morejo rešiti problema erozije socialnega kapitala. $\mathrm{Z}$ zavedanjem, da se zaloge socialnega kapitala lahko povečajo z različnimi oblikami in vrstami predvsem neformalnega izobraževanja odraslih, pa lahko prispevajo svoj delež $\mathrm{k}$ reševanju tega problema.

drugih disciplinah. Pri uporabi pojma socialnega kapitala, ki ima lahko pomembno razlagalno moč, bi bilo potrebno upoštevati vse dimenzije socialnega kapitala, zlasti pa se poleg pozitivnih zavedati tudi negativnih strani tega nevidnega kapitala.

Če izhajamo iz domneve, da je sodelovanje merilo in vir uspeha družbe, se je potrebno zavedati, da lahko številni socialni dejavniki, kot so revščina, bolezen, spol, etnična pripadnost, brezposelnost, imigracija ali starost, delu populacije preprečijo ali pa ga ovirajo pri sodelovanju $v$ skupnosti. To pomeni prepoznati, da strukturne neenakosti ovirajo sodelovanje. Č so izobraževalci odraslih senzibilni za izključene in marginalizirane, lahko $\mathrm{s}$ svojim delovanjem posredno senzibilizirajo tudi širšo javnost. Pri tem se postavlja
Izobraževanje odraslih naj tudi ozavešca marginalizirane skupine o njihovem položaju. vprašanje, kako lahko $\mathrm{z}$ izobraževanjem spodbujamo socialno vključenost marginaliziranih posameznikov in skupin. Pri iskanju odgovora se je potrebno zavedati, da je večina izobraževalne ponudbe za odrasle pripadnike marginaliziranih skupin običajno 
v "specialnih" razredih. To pomeni, da so segregirani, kljub prevladujoči politični retoriki integriranosti, pa tudi, da se med enakimi ustvarja socialni kapital, ki ima omejeno vrednost, in je $v$ nenehni nevarnosti, da bo razvrednoten. Izobraževalci odraslih bi lahko nadaljnjo segregacijo zaustavili $\mathrm{z}$ izobraževanjem in ozaveščanjem marginaliziranih o njihovem položaju $\mathrm{v}$ družbi ter $\mathrm{z}$ razvijanjem strategij za protidelovanje. Naslednji korak bi bil lahko povezovanje in sodelovanje socialnega kapitala marginaliziranih $\mathrm{z}$ drugimi vrstami socialnega kapitala $\mathrm{v}$ družbi.

Kritična teorija družbe je lahko zdravilo za nekritično sprejemanje funkcionalistične teorije socialnega kapitala, s tem ko poudarja strukturne dejavnike, ki ovirajo marginalizirane posameznike in družbene skupine, da bi Iahko črpali in prispevali svoj delež v zalogo kolektivnega socialnega kapitala. Hkrati pa teorija opozarja na zanemarjeno emancipatorno vlogo izobraževanja in dediščino Freira s tem, ko razkriva, da večina izobraževalne ponudbe za odrasle temelji na predpostavkah človeškega kapitala, pri čemer je poudarek predysem na znanjih in veščinah, ki večajo dobičkonosnost in konkurenčnost gospodarstva v državi.

\section{LITERATURA}

Adam, F. (1998). The relevance of social capital and intermediary structures for the creation of systemic competitiveness: Some lessons from Southern and Eastern-Central Europe. Družboslovne razprave, 26, 48-58.

Adam, F, Makarovič, M., Rončević, B., Tomšič, M. (2001). Socio-kulturni dejavniki razvojne uspešnosti. Slovenija v evropski perspektivi. Ljubljana: Znanstveno in publicistično središče.

Becker, G. S. (1967). Investment in Human Capital. Journal of Political Economy, št. 70, str. 9-49.

Benn, R. (2000). The genesis of active citizenship in the learning society. Studies in the Education of Adults, št. 2, str. 24l-256.

Berger, P. L., Luckmann, T. (1999). Modernost, pluralizem in kriza smisla. Ljubljana: Nova revija, Zbirka Paradigme.

Bourdieu, P. (1979). The Inheritors. Chicago: The University of Chicago Press.

Bourdieu, P. (1986). The Forms of Capital. V Richardson, J. (ed.). Handbook of Theory and Research for the Sociology of Education. Westport: Greenwood Press,

Brown, P. (1995). Cultural Capital and Social Exclusion: Some Obseravtions on Recent Trends in Education, Employment and the Labour Market. Work Employment and Society, st. 1, str. 29-51.

Coleman, S. J. (1988). Social Capital in the Creation of Human Capital. American Journal of Sociology, št. 94, str. 95-120.

Comparative studies on lifelong learning policies (1997). Tokyo, Hamburg: National Institute for Educational Research of Japan, Unesco Institute for Education.

Etzioni, A. (1995). The Spirit of Community. London: Fontana Press.

Fukuyama, F. (1995). Trust: The Social Virtues and the Creation of Prosperity. London: Hamish Hamilton.

Hanžek, M., Gregorčič, M. (ur.) (2001). Poročilo o človekovem razvoju - Slovenija 2000-2001. Ljubljana: Urad RS za makroekonomske analize in razvoj, United Nations Development Programme.

Hlebec, V., Ferligoj, A. (1996). Kvaliteta merjenja družbenih omrežij. V Kramberger, A. (ur.). Slovenska država, družba in javnost. Ljubljana: Fakulteta za družbene vede, str. 151-162.

Iglič, H., Rus, A. (2000). From elite reproduction to elite adaptation: the dynamics of change in personal networks of Slovenian elites. Družboslovne razprave, št. 32-33, str. 181-197.

Kanjuo Mrčela, A. (2001). Socialni kapital in lastniške strategije v slovenskih podjetjih. V Satnojević, M. (ur.). Uspešna nedozorelost. Ljubljana: Fakulteta za družbene vede, str. 162-189.

Lister, R. (1998). From Equality to Social Inclusion: New Labour and the Welfare State. Critical Social Policy, št. 2, str. 15-23.

Možina, E. (2000). Pismenost odraslih v Sloveniji. IB revija, št. 3-4, str. 28-40.

Nastran Ule, M. (2000). Sodobne identitete v vrtincu diskurzov. Ljubljana: Znanstveno in publicistično središče.

OECD (2001). The Well-being of Nations. The role of human and social capital. Paris: Centre for Educational Research and Innovation, Organisation for Economic Co-operation and Development,

Putnam, R. D. (1995). Bowling alone. America's declining social capital. Journal of Democracy, št. 1, str. 
65-78.

Putnam, R. D. (1993), Making Democracy Work. Princeton, New Jersey: Princeton University Press.

Riddell, S., Baron, S., Wilson, A. (1999). Social capital and people with learning difficulties. Studies in the Education of Adults, št. 1, str. 49-65.

Salamon, L. M.; Anheier, H. K. (1994). The Emerging Sector. The Non-profit Sector Comparative Research. Baltimore: The Johns Hopkins University Press.

Schuller, T., Field, J. (1998). Social capital, human capital and the learning society. International Journal of Lifelong Education, Vol. 17, št. 4, str. 226-235.

www.europa.eu.int/comm/education/life

www.mzt.si/mzt/tenders/crp/2001/razp-crp-konkur01.html 